BASIC RESEARCH

\title{
Effects of eplerenone on transcriptional factors and mRNA expression related to cardiac remodelling after myocardial infarction
}

\author{
S Enomoto, M Yoshiyama, T Omura, R Matsumoto, T Kusuyama, S Kim, Y Izumi, \\ K Akioka, H Iwao, K Takeuchi, J Yoshikawa
}

See end of article for authors' affiliations

Correspondence to: Dr Minoru Yoshiyama, Department of Internal Medicine and Cardiology, Osaka City University Medical School, 1-4-3 Asahimachi, Abeno-ku, Osaka 545-8585, Japan; yoshiyama@ med.osaka-cu.ac.jp

Accepted 13 January 2005 Published Online First 29 March 2005

Objective: To examine the effects of eplerenone, a selective aldosterone blocker, on cardiac function after myocardial infarction (MI) and myocardial remodelling related transcriptional factors and mRNA expression in non-infarcted myocardium.

Methods: MI was induced by ligation of the coronary artery in Wistar rats. Rats were randomly assigned to a vehicle treated group or an eplerenone treated group $(100 \mathrm{mg} / \mathrm{kg} /$ day)

Results: At four weeks after MI, left ventricular (LV) end diastolic pressure, LV weight, and LV end diastolic dimension were increased in MI rats. Eplerenone significantly reduced the increase in LV end diastolic pressure, LV weight, and LV end diastolic dimension. In the MI rats the decreased ejection fraction indicated systolic dysfunction and the increased $E$ wave to $A$ wave ratio and $E$ deceleration rate indicated diastolic dysfunction. Eplerenone significantly attenuated this systolic and diastolic dysfunction. Myocardial interstitial fibrosis, transcriptional activities of activator protein 1 and nuclear factor $\kappa B$, and mRNA expression of monocyte chemoattractant protein 1, plasminogen activator inhibitor 1, atrial natriuretic peptide, brain natriuretic peptide, and collagen types I and III were significantly increased at four weeks after MI. Eplerenone significantly attenuated interstitial fibrosis and suppressed transcriptional activity and mRNA expression of these genes.

Conclusions: When administered after Ml, eplerenone prevents cardiac remodelling accompanied by systolic and diastolic dysfunction and inhibits abnormal myocardial transcriptional activities and gene expression.

\begin{abstract}
A ldosterone has an important role in the pathophysiology of heart failure. It promotes sodium retention and loss of potassium and is implicated in the development of myocardial interstitial fibrosis. Structural remodelling of the interstitial collagen matrix is regulated in part by angiotensin II and aldosterone. ${ }^{1}$ Recent studies showed that aldosterone blockade reduces morbidity and mortality among patients with heart failure. In the RALES (randomised aldactone evaluation study), the aldosterone antagonist spironolactone reduced overall mortality in patients with severe heart failure. ${ }^{2}$ Eplerenone is a novel, highly selective aldosterone blocker that is devoid of side effects including gynaecomastia and breast pain attributed to spironolactone ${ }^{2}$ because of its low affinity for androgen and progesterone receptors. ${ }^{3}$ In the EPHESUS (eplerenone post-acute myocardial infarction heart failure efficacy and survival study) eplerenone reduced morbidity and mortality among patients with acute myocardial infarction (MI) complicated by left ventricular (LV) dysfunction and heart failure. ${ }^{4}$ However, little is known about the molecular mechanism of eplerenone in cardiac remodelling after MI.

We and other investigators have shown that angiotensin converting enzyme inhibitor (ACEI) and angiotensin II type 1 receptor blocker $(\mathrm{ARB})$ prevent cardiac remodelling after $\mathrm{MI}$ and suppress increases in mRNA expression of atrial natriuretic peptide (ANP) and collagen types I and III. Non-infarcted myocardial activator protein 1 (AP-1) and nuclear factor (NF) $\kappa B$ were activated and ACEI and ARB reduced transcriptional activation. ${ }^{6}$ These results suggest that myocardial AP-1 and NF- $\mathrm{KB}$ may be important transcriptional factors for the response to ventricular remodelling after MI.
\end{abstract}

In the present study, we examined the effects of eplerenone on LV remodelling in rats with MI. The purpose of this study was to elucidate the effects of eplerenone on myocardial remodelling related transcriptional factors and mRNA expression in non-infarcted myocardium after MI.

\section{METHODS}

Experimental animals and protocol

Male Wistar rats weighing 290-310 g were purchased from Clea Japan, Inc (Osaka, Japan). MI was induced by ligation of the left coronary artery as previously described. ${ }^{5}$ The same surgical procedure was performed in a sham group of rats, except that the suture around the coronary artery was not tied. Eplerenone was purchased from Pharmacia. Rats that survived overnight after coronary ligation were randomly divided into two groups: a vehicle treated group and an eplerenone treated group. Eplerenone was given in food. The dose of eplerenone $(100 \mathrm{mg} / \mathrm{kg} /$ day $)$ was selected based on the previous studies in which eplerenone provided major end organ protective effects in the heart and kidney of hypertensive rats. $^{7}$ A total 105 rats were used in the present experiments.

Abbreviations: ACEl, angiotensin converting enzyme inhibitor; ANP, atrial natriuretic peptide; AP-1, activator protein 1; ARB, angiotensin II type 1 receptor blocker; BNP, brain natriuretic peptide; EPHESUS, eplerenone post-acute myocardial infarction heart failure efficacy and survival study; LV, left ventricular; LVEF, left ventricular ejection fraction; $M C P-1$, monocyte chemoattractant protein $1 ; \mathrm{MI}$, myocardial infarction; NF, nuclear factor; PAl-1, plasminogen activator inhibitor 1; RALES, randomised aldactone evaluation study 


\section{Doppler echocardiographic studies and physiological studies}

Transthoracic echocardiograph studies were performed as previously described in detail. ${ }^{5}$ Echocardiograms were recorded with an echocardiographic system equipped with a 12.0 MHz phased array transducer (SONOS 5500; Philips Medical System, Best, the Netherlands) and read by a person blinded to treatment assignments. A two dimensional short axis view of the LV was recorded at the papillary muscle level to measure LV end diastolic dimension. LV ejection fraction (LVEF) and LV end diastolic volume were calculated by a modified Simpson's method, which is based on a four chamber view. Pulse wave Doppler spectra (E and A wave velocities) of mitral inflow were recorded from the apical four chamber view. The method of measuring the haemodynamic variables and infarct size has been described in detail. ${ }^{5}$ Rats with an infarct $<30 \%$ were excluded from analysis because they did not have typical LV remodelling.

\section{Histological and morphometric assessments}

Four weeks after MI, transverse myocardial sections $(5 \mu \mathrm{m}$ thick) were stained with collagen specific sirius red. Each field of non-infarcted myocardium was digitised and then the area of interstitial fibrosis was calculated as the ratio of the sum of the total area of interstitial fibrosis to all fields of the section. Perivascular areas were not included in this analysis. Average myocyte cross sectional area was calculated by computer assisted planimetry. A person blinded to the treatment assignments analysed these data. For immunohistochemical examination of monocyte chemoattractant protein 1 (MCP-1), the hearts were embedded in optimal cutting temperature compound, frozen in dry ice and acetone, and cut into $5 \mu \mathrm{m}$ sections. Polyclonal antibody to human MCP-1 (Santa Cruz Biotechnology, Santa Cruz, California, USA) was used as the primary antibody and the secondary antibody was antimouse polyvalent peroxidase conjugate (Nichirei, Tokyo, Japan). Peroxidase activity was visualised with 3,3'diaminobenzidine as the chromogen and nuclei were counterstained with methyl green.

\section{Electrophoretic mobility shift assays}

For the electrophoretic mobility shift assay, nuclear protein extracts of non-infarcted myocardium were prepared as described previously. ${ }^{6}$ Briefly, LV tissue was homogenised with a Dounce homogeniser in cold buffer A $(10 \mathrm{mmol} / \mathrm{l}$ HEPES (pH 7.9), $10 \mathrm{mmol} / \mathrm{l} \mathrm{KCl}, 0.1 \mathrm{mmol} / \mathrm{l}$ EDTA, $0.1 \mathrm{mmol} / \mathrm{l}$ EGTA, $1.5 \mathrm{mmol} / \mathrm{l} \quad \mathrm{MgCl}_{2}, 10 \mathrm{mmol} / \mathrm{l} \mathrm{NaF}$, $1 \mathrm{mmol} / \mathrm{l} \mathrm{Na} \mathrm{VO}_{4}, 0.5 \mathrm{mmol} / \mathrm{l}$ phenylmethylsulfonyl fluoride, $20 \mathrm{mmol} / \mathrm{l}$ glycerophosphate, $60 \mu \mathrm{g} / \mathrm{ml}$ aprotinin, and $2 \mu \mathrm{g} /$ $\mathrm{ml}$ leupeptin) with $1 \mathrm{mmol} / \mathrm{l}$ dithiothreitol. The tissue homogenates were allowed to swell on ice for 15 minutes, after which $62.5 \mu \mathrm{l}$ of $10 \%$ Nonidet P40 was added. The nuclear fractions were precipitated by centrifugation at $3500 \mathrm{~g}$ for 10 minutes at $4^{\circ} \mathrm{C}$ and then resuspended in cold buffer A with $0.2 \mathrm{mmol} / \mathrm{l}$ dithiothreitol. After centrifugation at $10000 \mathrm{~g}$ for 10 minutes at $4^{\circ} \mathrm{C}$, the supernatants containing nuclear protein were collected and stored at $-80^{\circ} \mathrm{C}$ until use.

The sequences of the double stranded oligonucleotides used in the present study were as follows: consensus AP-1, 5'-CGCTTGATGACTCAGCCGGAA-3'; consensus NF- $\kappa B$, 5'AGTTGAGGGGACTTTCCCAGGC-3'.

The oligonucleotide probes were labelled with $\left(\gamma^{32} \mathrm{P}\right)$-ATP at the $5^{\prime}$ end with $\mathrm{T} 4$ polynucleotide kinase. For the binding reactions, $5 \mathrm{mg}$ aliquots of nuclear extracts were incubated with probes and poly-(dI-dC) for 15 minutes at room temperature. The reaction mixtures were then loaded on to $4 \%$ non-denaturing polyacrylamide gels and electrophoresed at $200 \mathrm{~V}$ at $4^{\circ} \mathrm{C}$. The gels were dried and analysed by a
Table 1 Haemodynamic data and ventricular weights

\begin{tabular}{|c|c|c|c|}
\hline & \multirow{2}{*}{$\begin{array}{l}\text { Sham } \\
\text { operated }\end{array}$} & \multicolumn{2}{|l|}{ MI } \\
\hline & & Vehicle & Eplerenone \\
\hline $\begin{array}{l}\text { Number } \\
\text { Heart rate (beats/min) } \\
\text { Mean BP }(\mathrm{mm} \mathrm{Hg}) \\
\text { LVEDP }(\mathrm{mm} \mathrm{Hg}) \\
\text { Body weight }(\mathrm{g}) \\
\text { LVW }(\mathrm{mg} / \mathrm{g}) \\
\text { MI size }(\%)\end{array}$ & $\begin{array}{l}8 \\
370(14) \\
111(4) \\
3.7(0.4) \\
367(2) \\
2.21(0.02) \\
\text { NA }\end{array}$ & $\begin{array}{l}9 \\
381(18) \\
107(4) \\
14.8(1.1)^{* *} \\
361(3) \\
2.37(0.05)^{* *} \\
38(3)\end{array}$ & $\begin{array}{l}9 \\
394(17) \\
101(4) \\
11.2(0.6)^{* *}+\dagger \\
355(4)^{*} \\
1.98(0.04)^{* *}+\dagger \\
36(3)\end{array}$ \\
\hline \multicolumn{4}{|c|}{$\begin{array}{l}\text { Values are mean (SEM). } \\
{ }^{*} \mathrm{p}<0.05 v \text { Sham; * } \mathrm{p}<0.01 v \text { Sham; } \uparrow+<0.01 v \text { Vehicle. } \\
\mathrm{BP} \text {, blood pressure; LVEDP, left ventricular end diastolic pressure; LVW, } \\
\text { left ventricular weight/body weight; Ml, myocardial infarction; NA, not } \\
\text { applicable. }\end{array}$} \\
\hline
\end{tabular}

bioimaging analyser (BAS-2000, Fuji Photo Film, Tokyo, Japan).

\section{Northern blot analysis}

All procedures were performed as described in detail in our previous reports. ${ }^{5}$ In brief, the frozen tissue was homogenised with a Polytron homogeniser in denaturing solution $(4 \mathrm{~mol} / \mathrm{l}$ guanidinium thiocyanate, $25 \mathrm{mmol} / \mathrm{l}$ sodium citrate $(\mathrm{pH} 7.0)$, $0.1 \mathrm{~mol} / \mathrm{l} 2$-mercaptoethanol, and $0.5 \% \mathrm{~N}$-lauroylsarcosine). The homogenate was added to $2 \mathrm{~mol} / \mathrm{l}$ sodium acetate $(\mathrm{pH} 4)$ $(1 / 10 \mathrm{vol})$, water saturated phenol ( $1 \mathrm{vol})$, and chloroform $(1 / 2 \mathrm{vol})$ and centrifuged at $10000 \mathrm{~g}$ at $4{ }^{\circ} \mathrm{C}$ for 20 minutes. The resulting upper aqueous phase was twice precipitated with one volume of isopropanol. Then the RNA pellet was washed in $70 \%$ cold ethanol, dried, and dissolved in $0.1 \%$ diethyl pyrocarbonate treated water. Twenty micrograms of total RNA was denatured by incubating with $1 \mathrm{~mol} / \mathrm{l}$ deionised glyoxal and $50 \%$ dimethyl sulfoxide at $50^{\circ} \mathrm{C}$ for one hour, electrophoresed on a $1 \%$ agarose gel, and transferred to a nylon membrane. $\left({ }^{32} \mathrm{P}\right)$-dCTP labelled cDNA probes used in the present study were ANP, brain natriuretic peptide (BNP), collagen type I, collagen type III, plasminogen activator inhibitor 1 (PAI-1), MCP-1, and glyceraldehyde-3-phosphate dehydrogenase. The membranes were hybridised in a solution containing $50 \mathrm{mmol} / \mathrm{l}$ sodium phosphate $(\mathrm{pH} 7.4), 6 \times$ standard saline citrate, $5 \times$ Denhardt's solution, $0.1 \%$ sodium dodecyl sulfate, $200 \mu \mathrm{g} /$ $\mathrm{ml}$ denatured salmon sperm DNA, and the radiolabelled oligonucleotide probes at $42^{\circ} \mathrm{C}$ for 24 hours. The membranes were washed and exposed in BAS 2000.

\section{Statistical analysis}

Results were expressed as mean (SEM). Significance was determined by analysis of variance and the StudentNewman-Keuls test. Differences were considered significant at $\mathrm{p}<0.05$.

\section{RESULTS}

\section{Changes in haemodynamic variables and ventricular weights}

As table 1 shows, the size of the MI did not differ significantly between the two groups. Body weight was significantly decreased in the eplerenone group of MI rats $(p<0.05)$. The three groups did not differ significantly in mean blood pressure. LV end diastolic pressure was significantly higher in the vehicle group than in the sham operated rats $(p<0.01)$. Eplerenone significantly attenuated the increase in LV end diastolic pressure compared with the vehicle group $(p<0.01)$. LV weight corrected for body weight was significantly lower in the eplerenone group $(\mathrm{p}<0.01)$ than in the vehicle group. 
Table 2 Doppler echocardiographic assessment of left ventricular geometry and function

\begin{tabular}{|c|c|c|c|}
\hline & \multirow{2}{*}{$\begin{array}{l}\text { Sham } \\
\text { operated }\end{array}$} & \multicolumn{2}{|l|}{ MI } \\
\hline & & Vehicle & Eplerenone \\
\hline Number & 8 & 9 & 9 \\
\hline LVEDd (mm) & $6.5(0.3)$ & $11.8(0.6)^{\star *}$ & $10.0(0.5)^{* *} \dagger$ \\
\hline LVEDV $(\mu l)$ & $281(12)$ & $602(37)^{* *}$ & $507(32)^{* *} \dagger$ \\
\hline LVEF (\%) & $64(2)$ & $31(2)^{\star *}$ & $39(2)^{* *} \dagger$ \\
\hline $\mathrm{E}: \mathrm{A}$ & $1.5(0.1)$ & $10.3(1.5)^{* *}$ & $6.3(0.9)^{* *} \dagger$ \\
\hline E deceleration $\left(\mathrm{m} / \mathrm{s}^{2}\right)$ & $15(1)$ & $32(3)^{* *}$ & $27(1)^{* *} \dagger$ \\
\hline \multicolumn{4}{|c|}{$\begin{array}{l}\text { Values are mean (SEM). } \\
\text { ** } p<0.01 v \text { sham; } t p<0.05 v \text { vehicle. } \\
\text { LVEDd, left ventricular end diastolic dimension; LVEDV, left ventricular } \\
\text { end diastolic volume; LVEF, left ventricular ejection fraction. }\end{array}$} \\
\hline
\end{tabular}

\section{Doppler echocardiographic assessment}

Table 2 shows echocardiographic assessments of LV geometry and function at four weeks. LV end diastolic dimension and $\mathrm{LV}$ end diastolic volume significantly increased in the vehicle rats with MI compared with the sham operated rats $(\mathrm{p}<0.01)$. Eplerenone significantly reduced the increased LV end diastolic dimension and LV end diastolic volume in rats with MI. The vehicle rats with MI had significant systolic dysfunction as evaluated by decreased LVEF compared with the sham operated rats $(\mathrm{p}<0.01)$. Eplerenone significantly improved LVEF in rats with MI. Furthermore, the vehicle group had significant diastolic dysfunction $(p<0.01)$, as defined by an increased ratio of E wave to A wave (E:A ratio) and an increased $\mathrm{E}$ wave deceleration rate compared with the sham operated group. Eplerenone significantly improved the $\mathrm{E}$ :A ratio $(\mathrm{p}<0.05)$. E wave deceleration in the eplerenone group was significantly improved compared with the vehicle group.

\section{Histomorphometric findings in non-infarcted LV myocardium}

As fig 1 shows, sirius red staining showed a 2.1-fold increase in the cardiac myocyte cross sectional area, a measure of cell hypertrophy, and a 11.3-fold increase in the fraction of interstitial fibrosis in the non-infarcted myocardium compared with the sham operated rats. The treatment significantly attenuated cardiomyocyte hypertrophy (0.7-fold). The treatment also reduced the fraction of interstitial fibrosis (0.5-fold).

\section{Effects of eplerenone on transcriptional factors and mRNA expression in non-infarcted myocardium}

As fig 2 shows, MI significantly increased the myocardial transcriptional activity of AP-1 and NF- $\kappa \mathrm{B} 2.3$ - and 2.0-fold, respectively, in the non-infarcted myocardium $(p<0.01)$. Eplerenone significantly inhibited the increase in DNA binding activities of AP-1 $(76 \%, \mathrm{p}<0.01)$ and NF- $\kappa \mathrm{B}$ $(75 \%, p<0.01)$. Figure $3 \mathrm{~A}$ and table 3 show the results of cardiac gene expression. The mRNA expression of ANP, BNP, collagen types I and III, PAI-1, and MCP-1 significantly
Sham

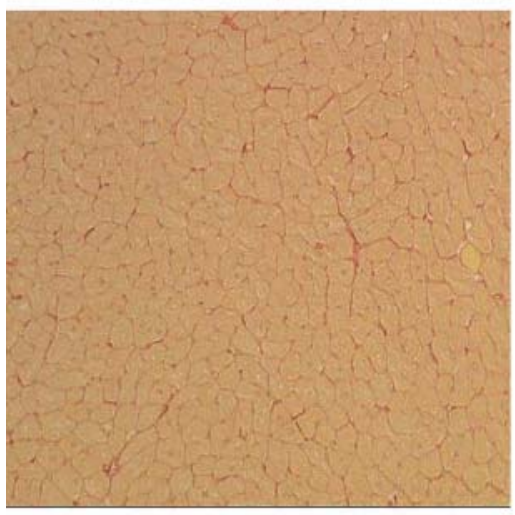

Vehicle

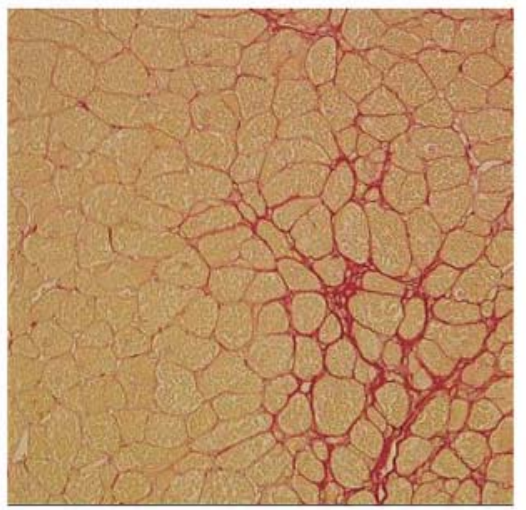

Ep

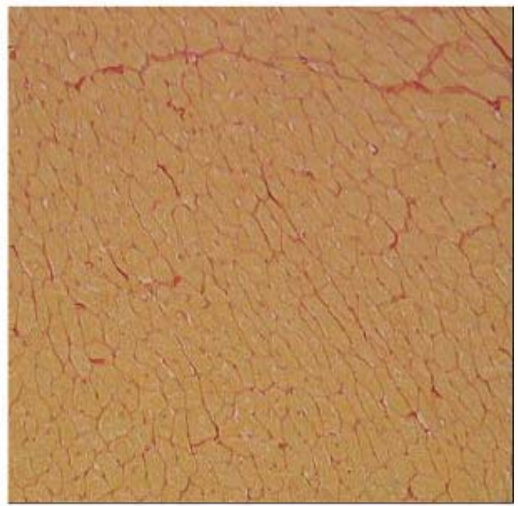

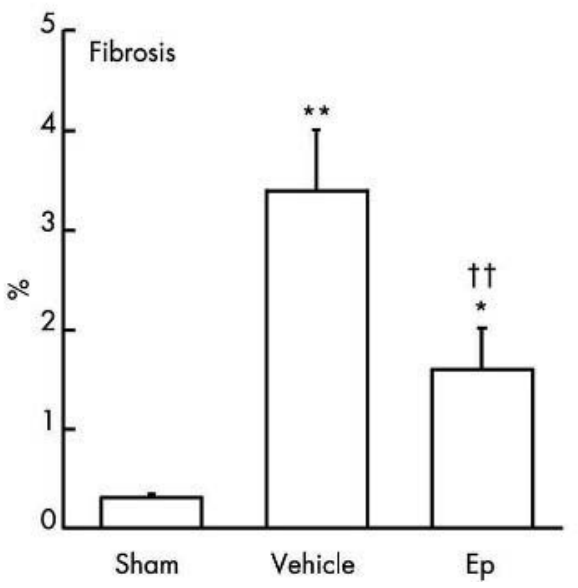

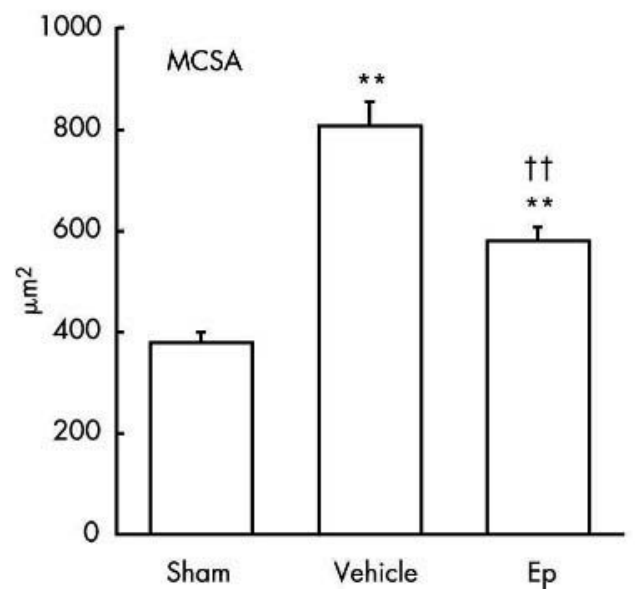

Figure 1 Histopathological analysis of the non-infarcted myocardium of rat left ventricle. Photomicrographs show sirius red stained cardiac sections from sham operated rats (Sham), infarcted rats treated with vehicle (Vehicle), and infarcted rats treated with eplerenone (Ep) ( $n=6$ in each group). Bar graphs show fraction of interstitial fibrosis and myocyte cross sectional area (MCSA). ${ }^{*} p<0.05 v$ sham; ${ }^{* *} p<0.01 v$ sham; ††p $<0.01 v$ vehicle. Values are mean (SEM). 

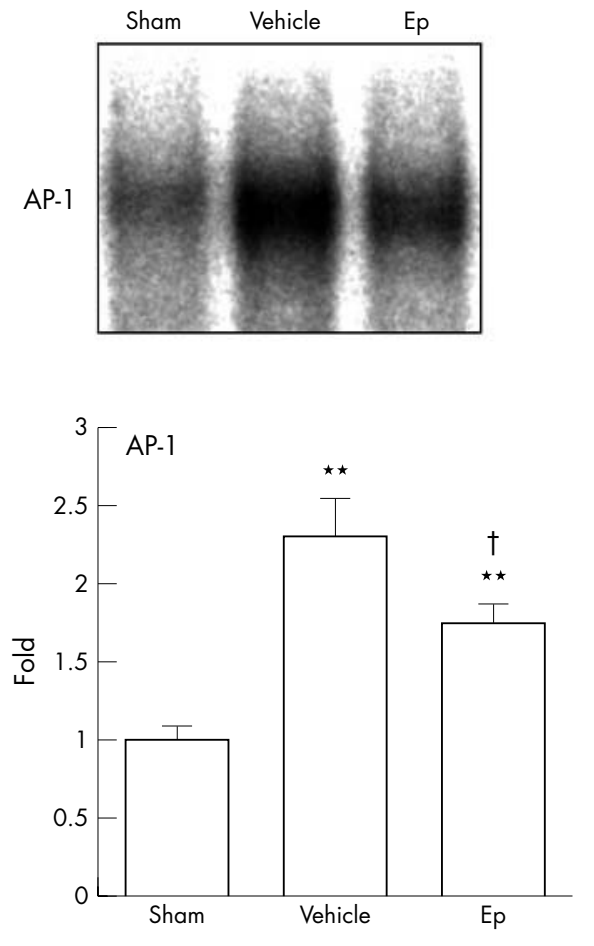
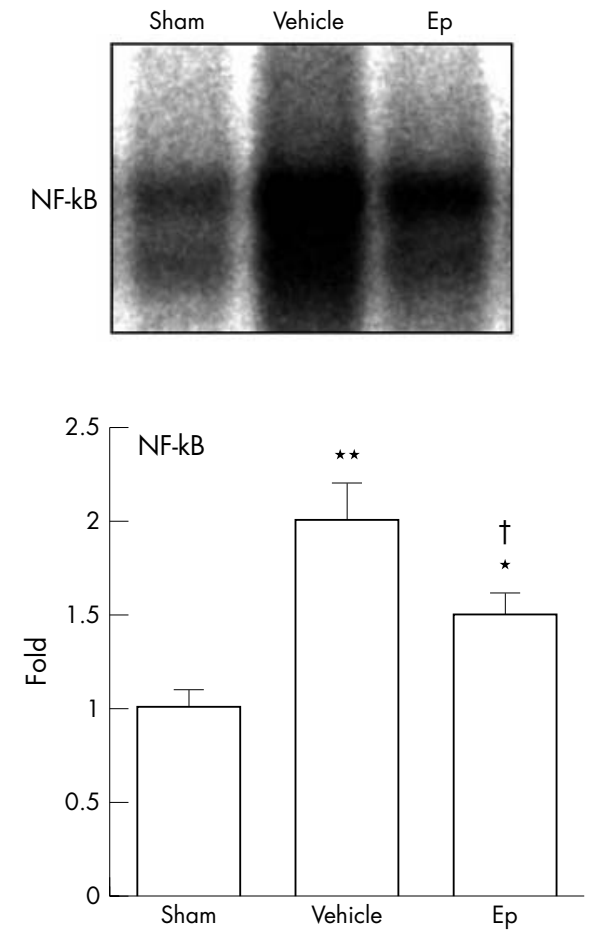

Figure 2 Effects of eplerenone on noninfarcted myocardial activator protein 1 (AP-1) and nuclear factor (NF) KB DNA binding activities at four weeks after myocardial infarction. Myocardial AP-1 and NF- $\kappa B$ DNA binding activities were compared in sham operated rats $(\mathrm{n}=8)$, infarcted rats treated with vehicle $(n=9)$, and infarcted rats treated with $\mathrm{Ep}(\mathrm{n}=9)$. The upper panels show representative autoradiographs of gel mobility shift assay of $A P-1$ and NF- $\kappa B$ DNA binding activities. Each bar represents mean (SEM) $(\mathrm{n}=6)$. ${ }^{*} \mathrm{p}<0.05 v$ sham; ${ }^{* *} \mathrm{p}<0.01 v$ sham; $\mathrm{tp}<0.05 v$ vehicle. increased 5.0-, 7.9-, 11.0-, 8.5-, 2.5-, and 3.4-fold, respectively, at four weeks after MI $(p<0.01)$. In the noninfarcted myocardium, eplerenone significantly attenuated the increased expression of ANP $(78 \%, \mathrm{p}<0.05)$, BNP $(82 \%$, $p<0.05)$, collagen I $(67 \%, p<0.01)$, collagen III $(68 \%$, $\mathrm{p}<0.01)$, PAI-1 $(63 \%, \mathrm{p}<0.05)$, and MCP-1 $(54 \%$, $\mathrm{p}<0.05)$ mRNA. Furthermore, immunohistochemical staining of MCP-1 was observed in interstitial fibrosis (fig 3B). Although MI increased MCP-1 expression, eplerenone reduced the increased protein expression of MCP-1.

\section{DISCUSSION}

Accumulating evidence shows that the cardiac reninangiotensin-aldosterone system is activated during LV remodelling after acute $\mathrm{MI}{ }^{8}$ Despite the outstanding success of ACEI in the treatment of congestive heart failure, the mortality of patients with congestive heart failure remains higher than that of normal subjects. This high mortality is partly due to the aldosterone escape phenomenon in patients who have received ACEI. ${ }^{10}$ The plasma angiotensin II concentration is not constantly decreased during long term treatment with ACEI, ${ }^{11}$ partly because angiotensin II may be produced by alternative pathways. ${ }^{12}$ Therefore, ARB or aldosterone receptor antagonists such as spironolactone may have additional advantages over ACEI. ${ }^{10}$

In addition to the indirect effects of aldosterone on cardiac function during heart failure caused by sodium retention, expansion of extravascular space, and hypervolaemia, some experimental evidence suggests that this hormone may exert direct effects on the heart. The mineralocorticoid receptor, which mediates the action of aldosterone, is expressed in cardiomyocytes, endothelial cells, and fibroblasts in the human heart. ${ }^{13}$ Brilla et al ${ }^{14}{ }^{15}$ reported that aldosterone led to the development of cardiac fibrosis in rats with $\mathrm{LV}$ hypertrophy. This effect results from a direct mineralocorticoid action on the heart, since spironolactone suppressed it at subpressor doses. ${ }^{14}$ The mechanism involved may be an aldosterone induced collagen synthesis, possibly by the cardiac fibroblasts. ${ }^{15}$
A recent study showed that adding treatment with spironolactone for acute MI improved LV chamber dilatation and reduced plasma procollagen. ${ }^{16}$ In the present study, we also observed that eplerenone reduced the gene expression of collagen types I and III and inhibited myocardial fibrosis in the non-infarcted myocardium. These findings are consistent with earlier observations that aldosterone is largely responsible for cardiac matrix protein production through a direct effect on the mineralocorticoid receptor.

Previous studies have shown that numerous growth associated genes responsible for cardiac remodelling, such as proto-oncogenes, growth factors, contractile proteins, or extracellular matrices, are activated in non-infarcted myocardium after MI, indicating a contribution of the altered gene expressions in the process of cardiac remodelling. ${ }^{17-19}$ In the present study, we measured the DNA binding activity of AP- 1 and NF- $\kappa B$ as key transcriptional factors for cell regulation in a non-infarcted region during cardiac remodelling after MI. These transcriptional factors seems to be important not only in cardiomyocyte hypertrophy but also in cardiac fibrosis. ${ }^{20} 21$ Eplerenone may attenuate the increased activation of non-infarcted myocardial AP-1 and NF- $\kappa$ B, thereby suggesting an important role of aldosterone in the activation of myocardial AP-1 and NF- $\mathrm{KB}$.

Compared with our previous reports, the effects of eplerenone on ventricular geometry, function, and myocardial mRNA expression are similar to those of ACEI or ARB, which are well known to prevent cardiac remodelling after MI. ${ }^{56}$ These results suggest that administration of a sufficient dose of eplerenone may have the same cardioprotective effects as ACEI and ARB in this animal model. Although there was no statistical difference, eplerenone decreased blood pressure. The improvement of haemodynamic function also seems to contribute to the prevention of cardiac remodelling after MI. Body weight was significantly reduced in the eplerenone treated group compared with the sham operated group. A similar result has been previously reported in the eplerenone treated MI rat. ${ }^{22}$ We suppose that the effect of eplerenone on body weight was likely mediated in part by 
A

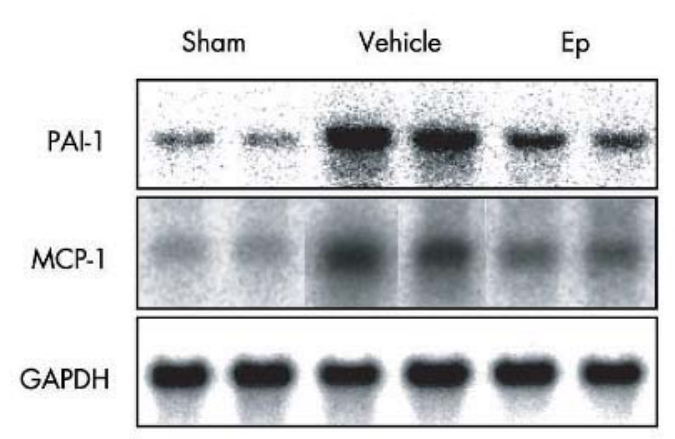

B
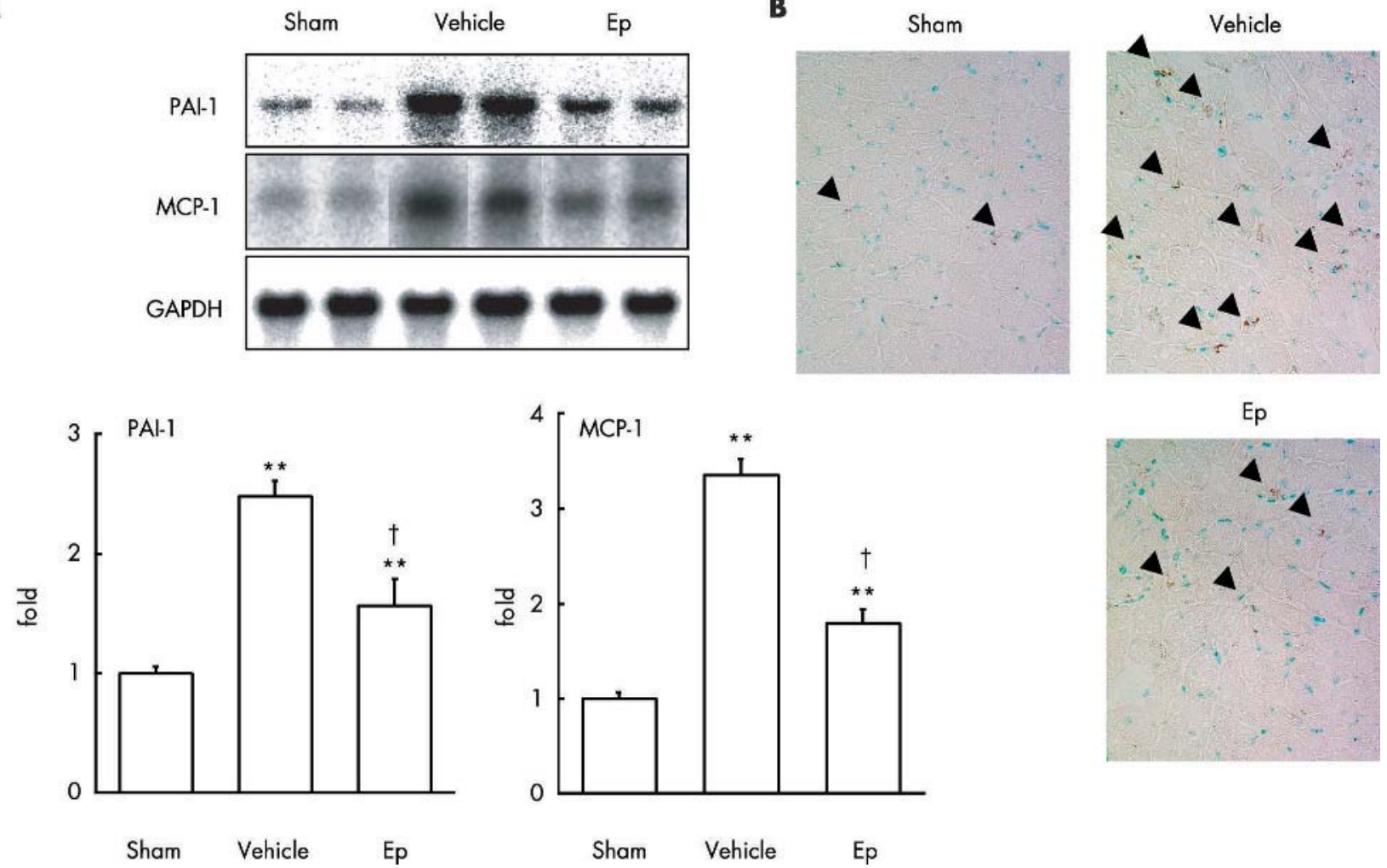

Figure 3 (A) Effects of eplerenone on non-infarcted myocardial mRNA expression at four weeks after myocardial infarction ( $\mathrm{n}=6$ in each group). Myocardial mRNA expression of plasminogen activator inhibitor 1 (PAl-1) and monocyte chemoattractant protein 1 (MCP-1) were compared in sham operated rats, infarcted rats treated with vehicle, and infarcted rats treated with Ep. Each panel shows a representative autoradiogram of northern blot analysis of PAI-1 and MCP-1. **p $<0.01 v$ sham; $\uparrow p<0.05 v$ vehicle. Values are mean (SEM). (B) Immunohistochemical staining for MCP-1 antigen in the non-infarcted myocardium. Arrows denote positive staining for MCP-1.

the reduction of water retention as a diuretic. In addition, the diuretic effect of eplerenone may cause alterations in loading conditions that affect LVEF and the E:A ratio. Reduction in preload or afterload may partly contribute to improvement of E:A ratio or LVEF, respectively.

Interestingly, MCP-1 is highly upregulated in the nonischaemic myocardium. Monocyte derived macrophages and mast cells may produce cytokines and growth factors necessary for fibroblast proliferation and neovascularisation, leading to effective repair and scar formation..$^{23}$ In failing hearts, MCP-1 has been shown to be increased in humans ${ }^{24}$ as well as in animal models. ${ }^{25}{ }^{26}$ Hayashidani $e t ~ a l^{27}$ reported that MCP-1 expression contributes to LV remodelling and failure after MI, potentially through increased cardiac fibrosis by way of enhanced transforming growth factor $\beta$ and matrix

Table 3 Gene expression after myocardial infarction

\begin{tabular}{|c|c|c|c|}
\hline & \multirow{2}{*}{$\begin{array}{l}\text { Sham } \\
\text { operated }\end{array}$} & \multicolumn{2}{|l|}{ MI } \\
\hline & & Vehicle & Eplerenone \\
\hline $\begin{array}{l}\text { ANP } \\
\text { BNP } \\
\text { Collagen I } \\
\text { Collagen III } \\
\text { PAl-1 } \\
\text { MCP-1 }\end{array}$ & $\begin{array}{l}1.00(0.07) \\
1.06(0.07) \\
1.00(0.06) \\
1.00(0.06) \\
1.00(0.04) \\
1.00(0.05)\end{array}$ & $\begin{array}{l}4.96(0.41)^{* *} \\
7.92(0.6)^{* *} \\
10.95(1.16)^{* *} \\
8.49(0.71)^{* *} \\
2.48(0.13)^{* *} \\
3.36(0.16)^{* *}\end{array}$ & $\begin{array}{l}3.88(0.29)^{* *} \dagger \\
6.50(0.29)^{* *} \dagger \\
7.31(0.76)^{* *} \dagger \dagger \\
5.73(0.25)^{* *} \dagger \dagger \\
1.57(0.21)^{* *} \dagger \\
1.80(0.12)^{* *} \dagger\end{array}$ \\
\hline \multicolumn{4}{|c|}{$\begin{array}{l}\text { Values are mean (SEM). } \\
{ }^{*} p<0.05 v \text { sham; }{ }^{* *} \mathrm{p}<0.01 v \text { sham; } \mathrm{tp}<0.05 v \text { vehicle; } \dagger+\mathrm{p}<0.01 v \\
\text { vehicle. } \\
\text { ANP, atrial natriuretic peptide; BNP, brain natriuretic peptide; MCP-1, } \\
\text { monocyte chemoattractant protein } 1 \text {; PAl-1, plasminogen activator } \\
\text { inhibitor } 1 .\end{array}$} \\
\hline
\end{tabular}

metalloproteinase 9 expression. They suggest that sustained MCP-1 expression can lead to sustained cytokine expression and inflammatory responses that in turn lead to myocardial damage. In the present study, eplerenone attenuated the increase in MCP-1 expression in MI, which may be involved in the inhibition of myocardial fibrosis and the resultant LV failure.

PAI- 1 regulates the plasminogen activator-plasmin system, which has been implicated as an important modulator during cardiac repair after MI. Regional PAI-1 induction may contribute to the progression of tissue fibrosis. ${ }^{28}$ Takeshita et al $^{29}$ reported less development of cardiac fibrosis after MI in mice deficient in PAI-1, suggesting that PAI-1 deficiency may prevent the increase of collagen deposition by accelerating matrix degradation. Therefore, the increased expression of cardiac PAI-1 may contribute to progression of cardiac fibrosis in the repair process after MI. A previous study has suggested that activation of the renin-angiotensin-aldosterone system increases PAI-1 through endogenous aldosterone..$^{30}$ In the current study, eplerenone was associated with attenuation of PAI-1 expression, which may contribute to the inhibition of cardiac fibrosis.

In conclusion, eplerenone prevented LV dysfunction and remodelling after MI. Our results suggest that aldosterone may be partially associated with myocardial remodelling accompanied by the activation of AP- 1 and NF- $\kappa B$ and the gene expression of MCP-1, PAI-1, ANP, BNP, and collagen types I and III.

\section{ACKNOWLEDGEMENTS}

This work was supported in part by grant in aid for scientific research (No 14570684, 15590766 and 16590709) from the Ministry of Education, Science, and Culture and a fund for medical research 
from the Osaka City University Medical Research Foundation. We thank Mihoko Watanabe and Azusa Inagaki for providing technical assistance.

\section{Authors' affiliations}

S Enomoto, M Yoshiyama, T Omura, R Matsumoto, T Kusuyama, K Akioka, K Takeuchi, J Yoshikawa, Department of Internal Medicine and Cardiology, Osaka City University Medical School, Osaka, Japan S Kim, Y Izumi, H Iwao, Department of Pharmacology, Osaka City University Medical School, Osaka, Japan

\section{REFERENCES}

1 Weber KT, Brilla CG. Pathological hypertrophy and cardiac interstitium fibrosis and renin-angiotensin-aldosterone system. Circulation 1991;83:1849-65.

2 Pitt B, Zannad F, Remme WJ, et al. The effect of spironolactone on morbidity and mortality in patients with severe heart failure. Randomized aldactone evaluation study investigators. N Engl J Med 1999;341:709-17.

3 De Gasparo M, Joss U, Ramjoue HP, et al. Three new epoxy-spirolactone derivatives: characterization in vivo and in vitro. J Pharmacol Exp Ther 1987;240:650-6.

4 Pitt B, Remme W, Zannad F, et al. Eplerenone, a selective aldosterone blocker in patients with left ventricular dysfunction after myocardial infarction. N Engl J Med 2003;348:1309-21.

5 Yoshiyama M, Takeuchi K, Omura T, et al. Effects of candesartan and cilazapril on rats with myocardial infarction assessed by echocardiography. Hypertension 1999;33:961-8.

6 Yoshiyama M, Omura T, Takeuchi K, et al. Angiotensin blockade inhibits increased JNKs, AP-1 and NF-kappa B DNA-binding activities in myocardial infarcted rats. J Mol Cell Cardiol 2001;33:799-810.

7 Rocha R, Rudolph AE, Frierdich GE, et al. Aldosterone induces a vascular inflammatory phenotype in the rat heart. Am J Physiol Heart Circ Physiol 2002;283:H1802-10.

8 Patel AR, Konstam MA. Recent advances in the treatment of heart failure. Circ J 2002;66:117-21.

9 Staessen J, Lijnen P, Fagard R, et al. Rise in plasma concentration of aldosterone during long-term angiotensin II suppression. J Endocrinol 1981;91:457-65.

10 Pitt D. ACE inhibitor co-therapy in patients with heart failure: rationale for the randomized aldactone evaluation study (RALES). Eur Heart J 1995;16(suppl N): 107-10.

11 Biollaz J, Brunner HR, Gavras I, et al. Antihypertensive therapy with MK 421 angiotensin II-renin relationships to evaluate efficacy of converting enzyme blockade. J Cardiovasc Pharmacol 1982;4:966-72.

12 Urata H, Healy B, Stewart RW, et al. Angiotensin II-forming pathways in normal and failing human hearts. Circ Res 1990;66:883-90.

13 Lombes $M$, Alfaidy N, Eugene $E$, et al. Prerequisite for cardiac aldosterone action. mineralocorticoid receptor and 11 beta-hydroxysteroid dehydrogenase in the human heart. Circulation 1995;92:175-82.
14 Brilla CG, Matsubara LS, Weber KT. Anti-aldosterone treatment and the prevention of myocardial fibrosis in primary and secondary hyperaldosteronism. J Mol Cell Cardiol 1993;25:563-75.

15 Brilla CG, Pick R, Tan LB, et al. Remodeling of the rat right and left ventricles in experimental hypertension. Circ Res 1990;67:1355-64.

16 Hayashi M, Tsutamoto T, Wada A, et al. Immediate administration of mineralocorticoid receptor antagonist spironolactone prevents post-infarct left ventricular remodeling associated with suppression of a marker of myocardial collagen synthesis in patients with first anterior acute myocardial infarction. Circulation 2003:107:2559-65.

17 Hanatani A, Yoshiyama M, Kim S, et al. Inhibition by angiotensin II type 1 receptor antagonist of cardiac phenotypic modulation after myocardial infarction. J Mol Cell Cardiol 1995;27:1905-14.

18 Gidh-Jain M, Huang B, Jain P, et al. Alterations in cardiac gene expression during ventricular remodeling following experimental myocardial infarction. J Mol Cell Cardiol 1998;30:627-37.

19 Yoshiyama M, Takeuchi K, Hanatani A, et al. Differences in expression of sarcoplasmic reticulum $\mathrm{Ca} 2+-\mathrm{ATPase}$ and $\mathrm{Na}+-\mathrm{Ca} 2+$ exchanger genes between adjacent and remote noninfarcted myocardium after myocardial infarction. J Mol Cell Cardiol 1997;29:255-64.

20 Omura T, Yoshiyama M, Yoshida K, et al. Dominant negative mutant of c-Jun inhibits cardiomyocyte hypertrophy induced by endothelin 1 and phenylephrine. Hypertension 2002;39:81-6.

21 Muller DN, Dechend R, Mervaala EM, et al. NF-kappaB inhibition ameliorates angiotensin II-induced inflammatory damage in rats. Hypertension 2000;35:193-201.

22 Delyani JA, Robinson EL, Rudolph AE. Effect of a selective aldosterone receptor antagonist in myocardial infarction. Am J Physiol Heart Circ Physiol 2001;281:H647-54.

23 Kakio T, Matsumori A, Ono K, et al. Roles and relationship of macrophages and monocyte chemotactic and activating factor/monocyte chemoattractant protein-1 in the ischemic and reperfused rat heart. Lab Invest 2000:80: 1127-36

24 Aukrust $\mathrm{P}$, Ueland T, Muller F, et al. Elevated circulating levels of C-C chemokines in patients with congestive heart failure. Circulation 1998;97:1136-43

25 Shioi T, Matsumori A, Kihara Y, et al. Increased expression of interleukin-1 beta and monocyte chemotactic and activating factor/monocyte chemoattractant protein-1 in the hypertrophied and failing heart with pressure overload. Circ Res 1997;81:664-71.

26 Behr TM, Wang X, Aiyar N, et al. Monocyte chemoattractant protein-1 is upregulated in rats with volume-overload congestive heart failure. Circulation 2000;102:1315-22.

27 Hayashidani S, Tsutsui $\mathrm{H}$, Shiomi T, et al. Anti-monocyte chemoattractant protein-1 gene therapy attenuates left ventricular remodeling and failure after experimental myocardial infarction. Circulation 2003;108:2134-40.

28 Creemers $\mathrm{E}$, Cleutiens J, Smits J, et al. Disruption of the plasminogen gene in mice abolishes wound healing after myocardial infarction. Am J Pathol 2000;156:1865-73

29 Takeshita K, Hayashi M, lino S, et al. Increased expression of plasminogen activator inhibitor-1 in cardiomyocytes contributes to cardiac fibrosis after myocardial infarction. Am J Pathol 2004;164:449-56.

30 Sawathiparnich P, Kumar S, Vaughan DE, et al. Spironolactone abolishes the relationship between aldosterone and plasminogen activator inhibitor- 1 in humans. J Clin Endocrinol Metab 2002;87:448-52. 